\title{
Influence of PEO and mechanical keying on the strength of AA 5052 alloy/polypropylene friction stir spot welded joints
}

DOI:

10.1016/j.ijadhadh.2019.04.002

\section{Document Version}

Accepted author manuscript

Link to publication record in Manchester Research Explorer

\section{Citation for published version (APA):}

Aliasghari, S., Skeldon, P., Zhou, X., \& Ghorbani, M. (2019). Influence of PEO and mechanical keying on the strength of AA 5052 alloy/polypropylene friction stir spot welded joints. International Journal of Adhesion and Adhesives. https://doi.org/10.1016/j.ijadhadh.2019.04.002

\section{Published in:}

International Journal of Adhesion and Adhesives

\section{Citing this paper}

Please note that where the full-text provided on Manchester Research Explorer is the Author Accepted Manuscript or Proof version this may differ from the final Published version. If citing, it is advised that you check and use the publisher's definitive version.

\section{General rights}

Copyright and moral rights for the publications made accessible in the Research Explorer are retained by the authors and/or other copyright owners and it is a condition of accessing publications that users recognise and abide by the legal requirements associated with these rights.

\section{Takedown policy}

If you believe that this document breaches copyright please refer to the University of Manchester's Takedown Procedures [http://man.ac.uk/04Y6Bo] or contact uml.scholarlycommunications@manchester.ac.uk providing relevant details, so we can investigate your claim.

\section{OPEN ACCESS}




\section{Accepted Manuscript}

Influence of PEO and mechanical keying on the strength of AA 5052 alloy/ polypropylene friction stir spot welded joints

S. Aliasghari, P. Skeldon, X. Zhou, M. Ghorbani

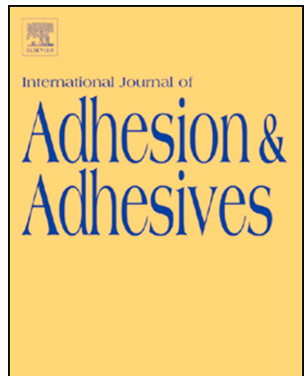

PII:

S0143-7496(19)30080-6

DOI:

https://doi.org/10.1016/j.ijadhadh.2019.04.002

Reference: $\quad$ JAAD 2366

To appear in: International Journal of Adhesion and Adhesives

Accepted Date: 12 April 2019

Please cite this article as: Aliasghari S, Skeldon P, Zhou X, Ghorbani M, Influence of PEO and mechanical keying on the strength of AA 5052 alloy/polypropylene friction stir spot welded joints, International Journal of Adhesion and Adhesives, https://doi.org/10.1016/j.ijadhadh.2019.04.002.

This is a PDF file of an unedited manuscript that has been accepted for publication. As a service to our customers we are providing this early version of the manuscript. The manuscript will undergo copyediting, typesetting, and review of the resulting proof before it is published in its final form. Please note that during the production process errors may be discovered which could affect the content, and all legal disclaimers that apply to the journal pertain. 
Influence of PEO and mechanical keying on the strength of AA 5052 alloy/polypropylene friction stir spot welded joints

S. Aliasghari ${ }^{\mathrm{a}, \mathrm{b}, \mathrm{c}}$, P. Skeldon ${ }^{\mathrm{c}}$, X. Zhou ${ }^{\mathrm{c}}$, M. Ghorbani ${ }^{\mathrm{b}}$,

${ }^{a}$ ASTeC, STFC Daresbury Laboratory, Daresbury, Warrington, Cheshire WA4 4AD, UK.

${ }^{b}$ Department of Materials Science and Engineering, Sharif University of Technology, P.O. Box 11365-9466. Azadi Avenue, 14588 Tehran, Iran.

${ }^{c}$ Corrosion and Protection Group, School of Materials, The University of Manchester, Oxford Rd., Manchester M13 9PL, England, U.K. 


\begin{abstract}
A study has been carried out of the effect of plasma electrolytic oxidation (PEO) on the strength of AA 5052 alloy/polypropylene joints prepared using friction stir spot welding (FSSW). The joint strengths were determined using lap-shear tests and failure modes were investigated using scanning electron microscopy. Comparisons were made between control joints prepared with the alloy in the as-rolled condition or the as-rolled condition with a mechanical key and with PEOtreated alloy, with or without a mechanical key. Mechanical keying alone, provided by infiltration of polymer into holes of either 3 or $4.5 \mathrm{~mm}$ diameter drilled in the alloy, yielded enhancements of the joint strength by a factor of 1.8 and 3.8, respectively, compared with the asrolled alloy. In contrast, PEO pre-treatment provided a much greater improvement in strength, by a factor of 21.3, with no significant influence of the presence of a mechanical key. The fracture of PEO-treated joints involved a mixture of de-bonding at the polymer/coating interface, cohesive failure within the coating and ductile failure of the polymer. The latter resulted from formation of gas bubbles within the polypropylene due to thermal degradation of the polymer during FSSW. In contrast, in the absence of PEO, the fracture path of the as-rolled, and also the as-rolled and mechanically keyed, joints passed along the alloy/polypropylene interface and through gas bubbles within the polymer. The enhanced strength of the PEO-treated joints resulted from the strong polypropylene/coating bond resulting from by flow of molten polymer into the coating porosity.
\end{abstract}

Keywords: aluminium alloy, polypropylene, friction stir spot welding, anodizing, plasma electrolytic oxidation.

\title{
1. Introduction
}

Joining of polymers, light metals and composites in multi-material components and structures is of interest in automobile and aircraft design for weight reduction [1, 2]. Various methods for joining dissimilar material have been investigated, such as adhesive bonding [3-6], mechanical fastening [7, 8] and welding-based methods [9-11]. The last includes friction stir spot welding 
(FSSW). FSSW in alloy to polymer joining involves applying a rotating tool under an applied load to the alloy side of the overlapped metal and polymer parts. The tool consists of a pin and shoulder. Due to frictional heating generated in the alloy by the tool, the polymer located beneath the tool is softened and melted. In contrast, the metal side of the joined region is not melted. The polymer can then flow into surface features of the alloy side, such as rolling lines, roughness created by grit blasting or pores of a porous surface.

FSSW has been employed to join AA 6181-T4 alloy to fibre-reinforced poly(phenylene sulphide (PPS)) laminate [12]. The joints revealed high strength, which depended on the tool rotational speed and joining time that affected the joint microstructure. Failure occurred by brittle fracture involving adhesive and cohesive failure at the joint interface. Investigations of FSSW AA 2024T3 alloy- fibre-reinforced PPS laminate joints showed that the joint strength was improved by inclusion of a PPS interlayer, which increased the bond area, and improved load distribution and mechanical interlocking [13]. Other work examined FFW magnesium alloy (AZ31)-glass and carbon fibre reinforced PPS joints, revealing microstructural changes in the alloy and polymer due to the thermomechanical effects of the joining process [14]. Studies of AZ91B-nylon joints showed that the temperature rise during FSSW can cause thermal degradation of the polymer leading to formation of bubbles within the polymer filled by gaseous reaction products [15]. The gas volume could be reduced by increasing the welding rate, rotational speed of the tool and the plunge depth. A method using a pre-threaded hole has been reported for filling exit holes, left by the FSSW process, with melted and re-solidified polymer was demonstrated using AA 5052carbon fibre-reinforced polypropylene joints [16]. Bonding was achieved by interlocking between the threaded hole and re-solidified polymer and formation of a reaction layer between the alloy and polymer within the hole. Higher bond strengths were achieved by increasing the tool rotational speed.

For joining of aluminium alloys to polymers using FSSW, surface treatment of the alloy is an important consideration. Various surface treatments are available, such as grit-blasting, conversion treatments, anodizing and plasma electrolytic oxidation (PEO). In previous FSSW studies, sand blasting [12] or grinding [13, 14] have been employed to assist bonding by removing surface layers and increase surface roughness. In contrast, PEO generates porous 
oxide-based coatings of several microns thickness that usually contain crystalline alumina [1720]. Such layers may covalently bond with a polymer [15, 21], while the porosity of the coating, ranging from the nanometre to micrometre scale [20], may assist mechanical interlocking between the polymer and the coating. The coatings are formed under a high voltage applied to the alloy, which is immersed in a suitable, usually aqueous, electrolyte. Short-lived microdischarges on the workpiece generate the coating material, which is produced by a combination of thermal oxidation, anodic oxidation and plasma-chemical processes reactions involving the substrate and electrolyte components.

Only limited investigation has been carried out on the use of PEO in aluminium alloy/polymer joining using FSSW [22]. The earlier work employed joints that included a mechanical key in addition to the PEO pre-treatment. In the present study the effect of PEO in the absence of a mechanical key is examined in joining of AA 5052 alloy with polypropylene. In order to assess the necessity of the key for obtaining high joint strength, comparisons were made between joints prepared with the alloy in the PEO-treated condition in the presence and absence of a mechanical key. Joints were also prepared with the as-rolled alloy with and without a mechanical key to demonstrate the strength enhancement provided by the PEO-treated surface. The joints were subjected to lap-shear tests to measure the joint strength, followed by fractographic examination to determine the failure mode.

\section{Experimental}

AA 5052 alloy and polypropylene (C30S grade - tensile strength $32 \mathrm{MPa}$ ) sheets, with a thickness of 2.0 and $2.8 \mathrm{~mm}$ respectively, were employed for the study. The top surface of the polypropylene sheet was embossed with fine decorative speckling. The alloy composition according to optical emission spectroscopy (OES) is given in Table 1. Specimens with dimensions of $70 \times 30 \mathrm{~mm}$ were cut from the alloy and polypropylene sheets. A hole of either 3 or $4.5 \mathrm{~mm}$ diameter was drilled through the middle of selected alloy specimens. The hole was located in the centre of the area to be joined and was used to form a mechanical key by infiltration of polymer during FSSW. 
Table 1. Composition of the AA 5052 alloy (wt.\%).

\begin{tabular}{|l|l|l|l|l|l|}
\hline $\mathrm{Mg}$ & $\mathrm{Cr}$ & $\mathrm{Fe}$ & $\mathrm{Si}$ & $\mathrm{Mn}$ & $\mathrm{Al}$ \\
\hline 2.34 & 0.2 & 0.23 & 0.06 & 0.006 & bal. \\
\hline
\end{tabular}

The PEO treatment was applied directly to the as-rolled alloy surface, since the resultant PEO coating is not affected significantly by the surface condition of the substrate. The treatment was carried out using a DC power supply source with a capacity of $600 \mathrm{~V}$ and $4 \mathrm{~A}$. An aqueous electrolyte was prepared by dissolving $10.5 \mathrm{~g} \mathrm{dm}^{-3} \mathrm{Na}_{2} \mathrm{SiO}_{3}$ (specific gravity 1.5 ) and $2.8 \mathrm{~g} \mathrm{dm}^{-3}$ $\mathrm{KOH}$ (ACS grades) ( $\mathrm{pH}$ 12.5) in deionised water. A double-walled glass cell was employed to contain the electrolyte, which had a volume of $0.6 \mathrm{dm}^{3}$. The electrolyte was stirred with a magnetic stirrer during PEO. The temperature of the electrolyte was kept at $25{ }^{\circ} \mathrm{C}$ by a flow of cold water through the cell wall. A stainless steel (type 304) plate of dimensions 5 x $12 \mathrm{~cm}$ was used as a counter electrode. The applied voltage was $300 \mathrm{~V}$; the treatment time was $10 \mathrm{~min}$. Previous work has shown that PEO under the selected conditions results in a non-uniform coating thickness in the range 10 to $30 \mu \mathrm{m}$ [22].

FSSW joints were prepared using a friction stir welding facility. The polypropylene and AA 5052 alloy specimens were clamped together with an overlap of $3 \times 3 \mathrm{~cm}$. The smooth surface of the polypropylene sheet faced the alloy. The tool (AISI Type H13 hot work tool steel) of $20 \mathrm{~mm}$ diameter was applied to the AA 5052 alloy side of the overlapped region at a rotation rate of $1000 \mathrm{rev} \mathrm{m^{-1 }}$ and plunged into the AA 5052 alloy at a rate of $20 \mathrm{~mm} \mathrm{~min}^{-1}$ for $4 \mathrm{~s}$. Under this condition, the tool did not reach the polymer. However, the resultant temperature rise of the specimen melted the polypropylene. The details of the arrangement of the specimens for the joining process have been published previously [22].

Lap-shear tests of the joints were carried out in a Hounsfield H10 KS $50 \mathrm{kN}$ Universal Testing Machine, with QMAT software. In order to ensure that the joints were subjected mainly to a shear stress, a rectangular piece of the alloy was inserted into the grip holding the end of the polymer. Similarly, a rectangular piece of the polymer was inserted into the grip holding the end of the alloy. A length of $1 \mathrm{~cm}$ of the alloy and polymer was present between the joined region 
and the grip. An extension rate of $0.5 \mathrm{~mm} \mathrm{~min}^{-1}$ was applied until joint failure and the load versus extension was recorded. The extension was determined from the displacement of the crosshead and included the extension in the alloy and polymer outside the joined region. Triplicate tests were carried out for each type of joint.

Alloy specimens prior to bonding were examined using Zeiss Evo 50 and Zeiss Ultra 55 scanning electron microscopes. Fracture parts after lap-tensile shear tests were examined using a Tescan MIRAJ field emission scanning electron microscope equipped with energy-dispersive Xray (EDX) analysis facilities. The fractured specimens were gold-coated to avoid charging during examination. EDX analyses were made in rectangular areas of dimensions 500 x $300 \mu \mathrm{m}$.

\section{Results and discussion}

3.1 Surface morphologies of the AA 5052 alloy before and after pre-treatment.

Figure 1 presents scanning electron micrographs of the as-rolled and PEO-treated AA 5052 surface. The rolled surface showed grooves and ridges typical of a rolled condition (Fig. 1 (a)). The PEO-treated surface revealed pores with diameters typically up to about $5 \mu \mathrm{m}$ (Fig 1 (b)). The pores are formed by dielectric breakdown and gas evolution during the PEO process. Pores of nanometre dimensions are probably also present that are unresolved by the present examination [20]. The numerous, short-lived microdischarges that occur during dielectric breakdown cause localized melting and growth of the coating, followed by rapid cooling and solidification, resulting in the formation of $\alpha-\mathrm{Al}_{2} \mathrm{O}_{3}$ and $\gamma-\mathrm{Al}_{2} \mathrm{O}_{3}$ [22]. The surface is also decorated by nodular conglomerates of silica-rich particles, which have an amorphous structure according to X-ray diffraction [22]. 

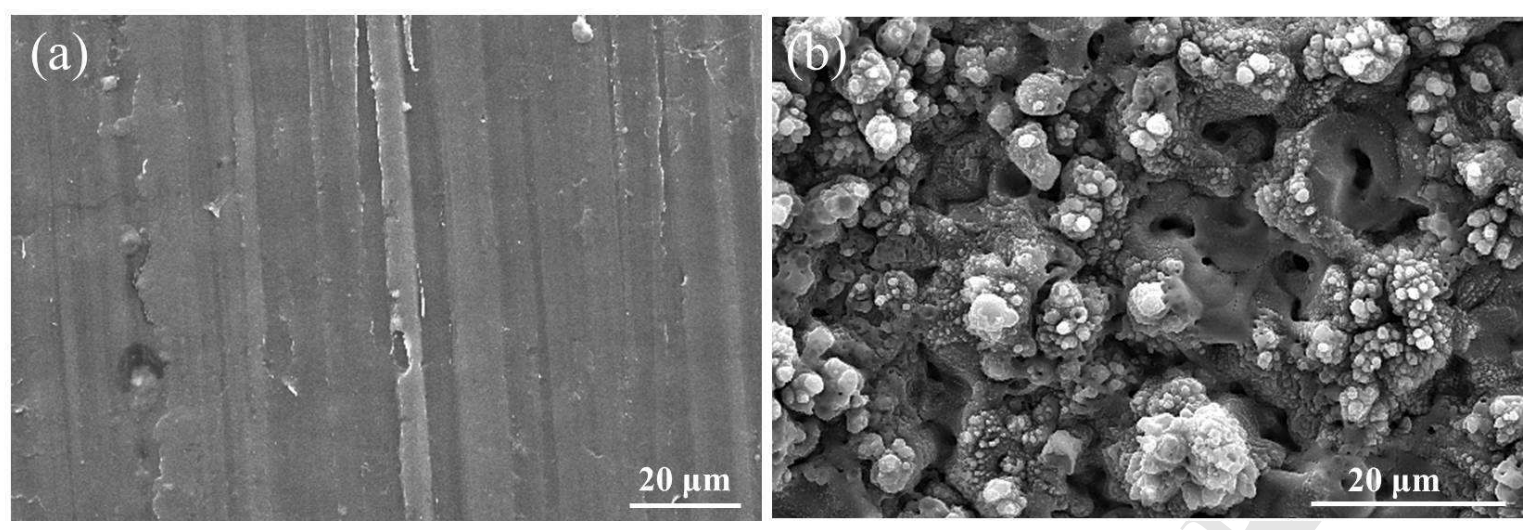

Figure 1. Scanning electron micrographs (secondary electrons) of the surface of the AA 5052 alloy: (a) as-rolled; (b) PEO-treated.

3.2 Lap-shear tensile tests and fractography of joints prepared using mechanically keyed alloy

Figure 2 shows typical examples of load-extension curves from the lap tensile shear tests of joints prepared with the as-rolled alloy, including specimens with a single 3 or $4.5 \mathrm{~mm}$ mechanical key. Table 2 presents the average, maximum and minimum failure loads from triplicate tests for each specimen condition, showing average failure loads of 62,112 and $238 \mathrm{~N}$ with no mechanical key, a $3 \mathrm{~mm}$ hole and a $4.5 \mathrm{~mm}$ hole, respectively. Thus, the mechanical keys increased the strength of the joints a factors of 1.8 and 3.8, respectively. The strength enhancements were accompanied by an increase in the extension at failure from about $0.2 \mathrm{~mm}$ with no hole to about $0.5 \mathrm{~mm}$ with the $4.5 \mathrm{~mm}$ hole. 


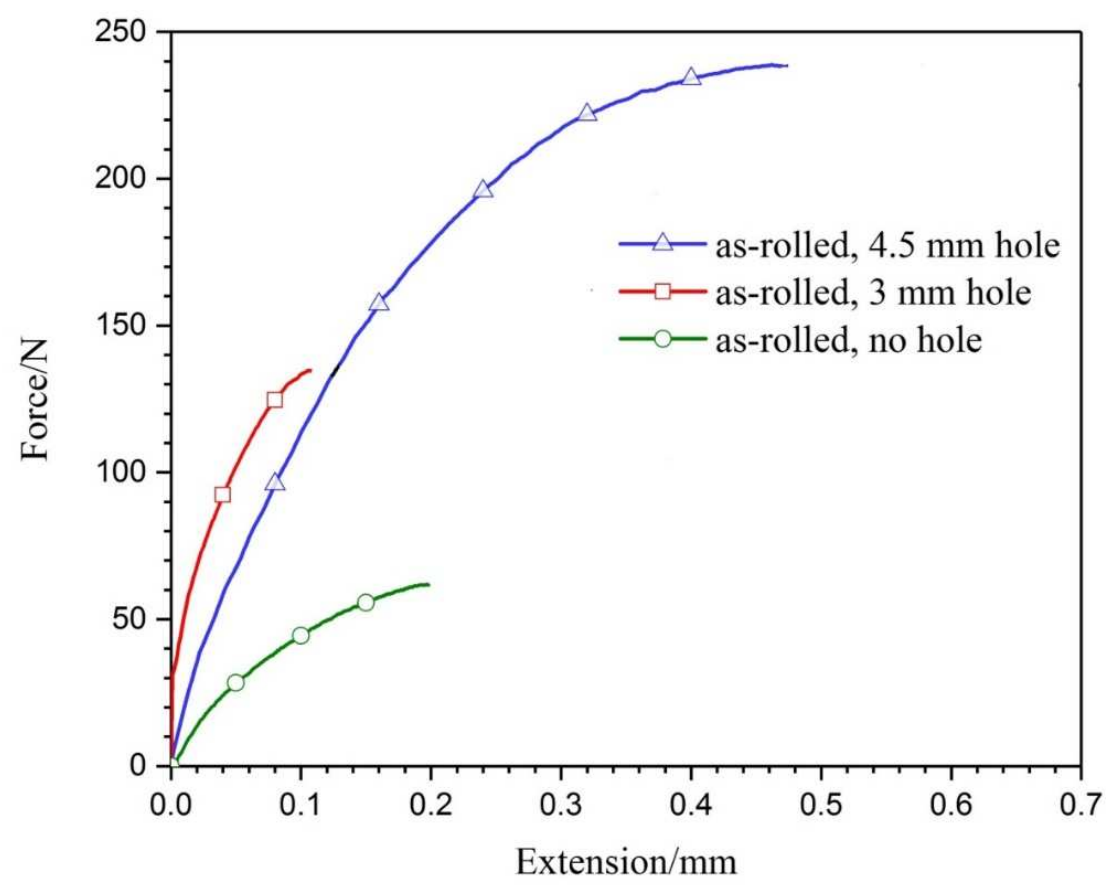

Figure 2. Force-extension curves from lap-shear tests of AA 5052 alloy/polypropylene joints with the alloy in the as-rolled (AR), AR with $3 \mathrm{~mm}$ mechanical key, and AR with $4.5 \mathrm{~mm}$ mechanical key conditions.

Figures 3 (a-c) show photographs of the fractured joints prepared using the as-rolled alloy with and without a mechanical key. The joints failed by debonding of the alloy and polypropylene due to weak adhesion. The dark spots on the polymer side of the fracture of the specimens prepared using a mechanical key are polymer pegs produced by flow of polymer into the keying holes in the alloy (Figs. 3 (b) and 3 (c)). 

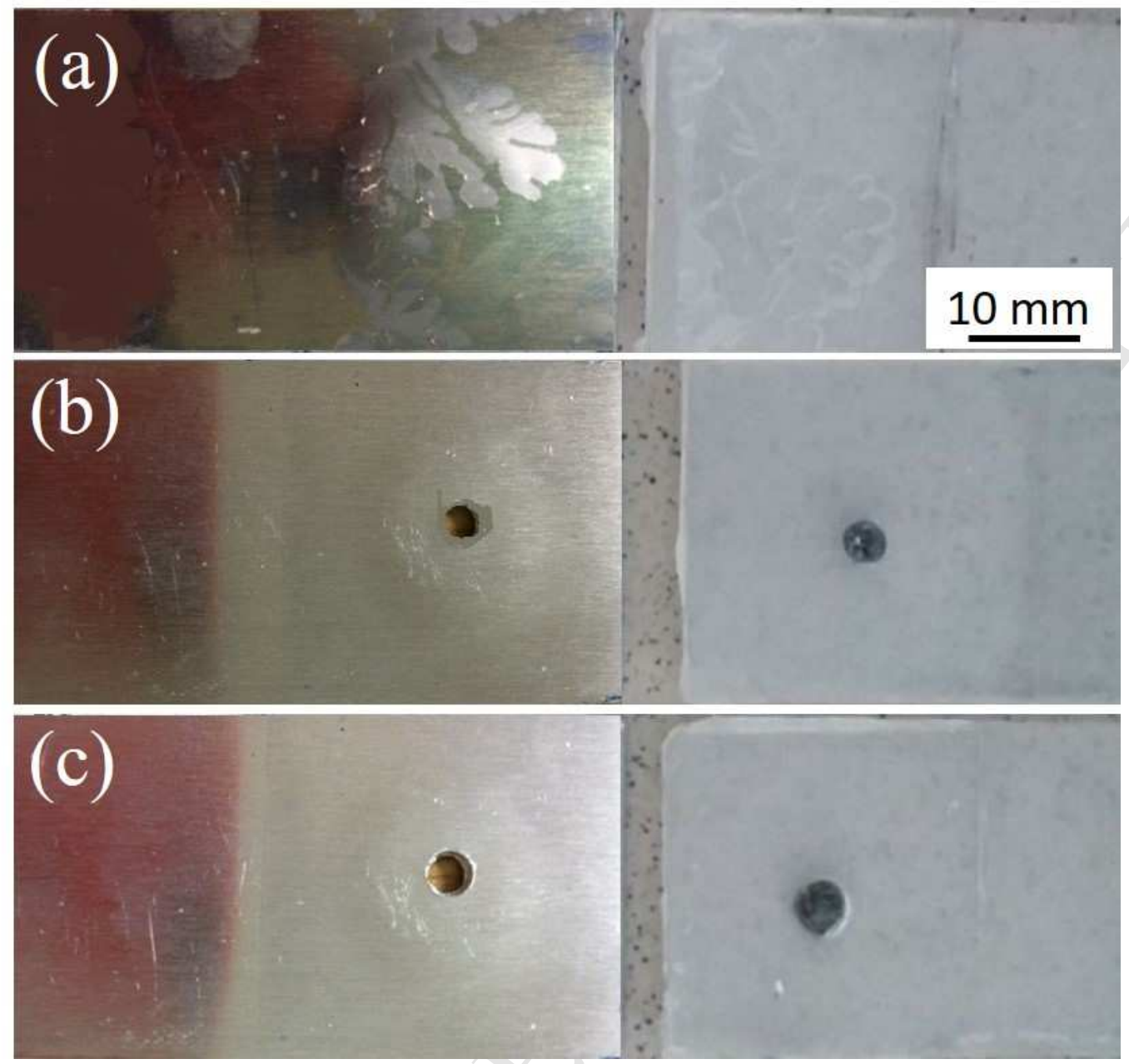

Figure 3. Photographs of fractured AA 5052 alloy/polypropylene joints with the alloy in the (a) as-rolled (AR), (b) AR with 3mm mechanical key and (c) AR with $4.5 \mathrm{~mm}$ mechanical key condition.

Figure 4 shows scanning electron micrographs of the alloy and polypropylene sides of the fractured joint with no mechanical key. Dark regions of residual polypropylene, with a dendritic appearance, were present on the aluminium side (Fig. 4 (a)), with matching features on the polypropylene side ((Fig. 4 (b)). These regions are locations of prior gas bubbles created by thermal decomposition, which can generate hydrogen and aliphatic and unsaturated hydrocarbons [23-25], with the reaction rate increasing rapidly with temperature [26]. If oxygen is available oxidative degradation may also occur, producing $\mathrm{CO}, \mathrm{CO}_{2}$ and $\mathrm{H}_{2} \mathrm{O}$ [23]. The failure 
in the vicinity of a bubble leaves a thin layer of polymer attached to the alloy and a relatively deep cavity within the polypropylene. The bubbles appear to nucleate at the joint edges, where the pressure within the polymer from the applied load on the rotating tool during FSSW is lower. The availability of oxygen may also favour bubble initiation at these locations. The bubbles form close to the alloy surface where heating is greatest, expand into the overlying molten polymer and grow toward the inner parts of the joint. The thin polymer layer that remains on the alloy is possibly formed by flow of molten polymer just after FSSW is terminated. The gas pressure acting on the layer may provide the comparatively good adhesion to the substrate. At regions on the alloy side of the joint where no polymer remained, rolling lines were observable on the alloy surface, which were replicated on the polymer side by flow of polymer into the grooved alloy surface during FSSW (Fig. 4 (c)). Figure 4 (d) shows bubbles within the polymer side of the fracture in more detail. The smooth regions, which reveal replicas of the rolling lines on the alloy, represent polymer originally bonded to the alloy. The textured regions are the surfaces of cavities in the re-solidified polymer. Ductile fracture of the polymer occurs at the edges of the two regions where the polymer has been detached from the thin layer that remains on the alloy surface. 


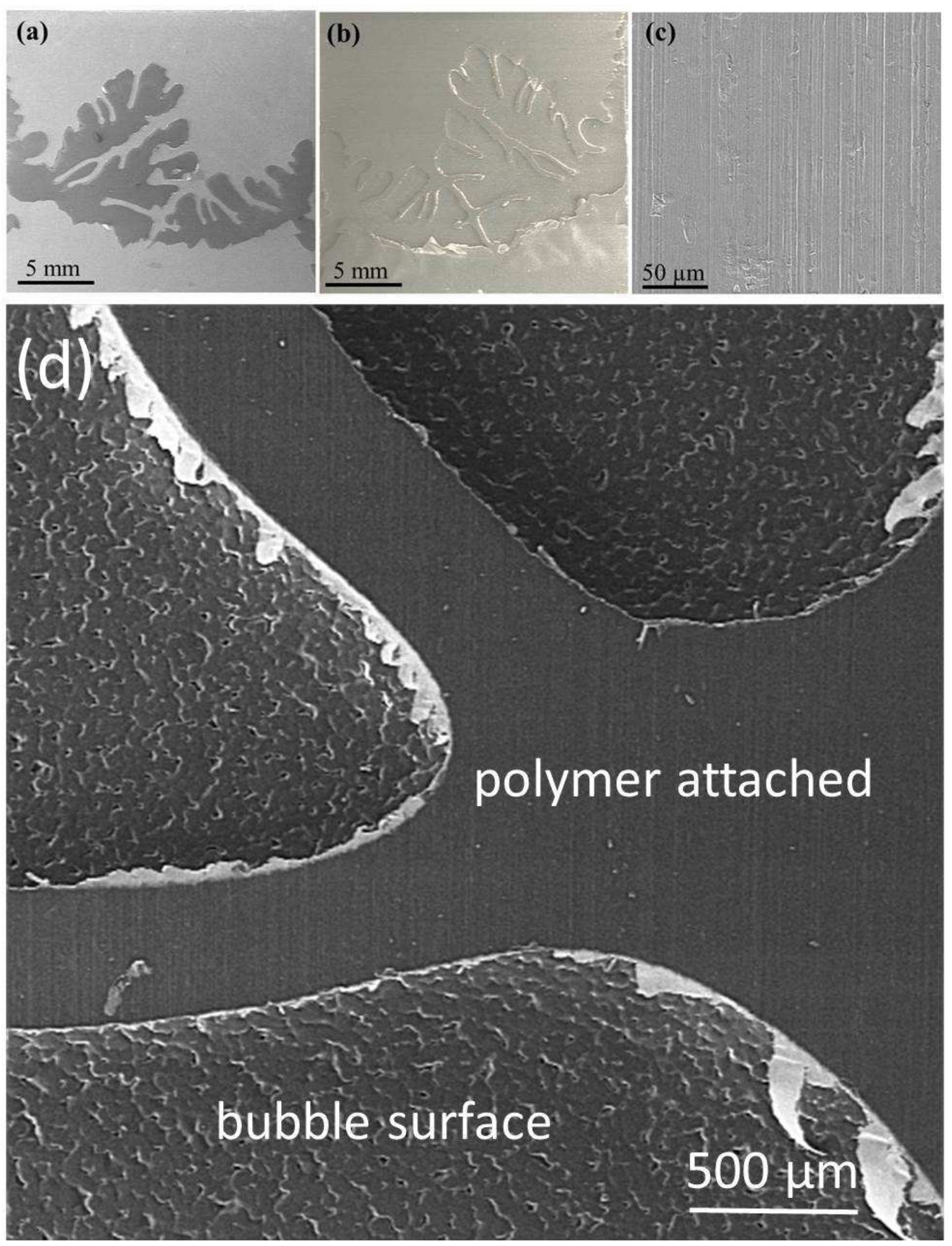


Figure 4. Scanning electron micrographs of the fracture surfaces of the as-rolled AA 5052 alloy/polypropylene joint: (a) alloy side; (b, c) polypropylene side.

The presence of the bubbles leads to a non-uniform shear stress at the alloy/polypropylene interface during lap-shear tests. Lower shear stresses occur beneath the bubbles, since the applied force is divided between the relatively thin polymer layer attached to the alloy and the much thicker residual polymer above the bubble. Due to the shielding of stress by bubbles, shear stresses are increased at adjacent bubble-free interface regions. The bubble defects can also give rise to stress concentration effects, further enhancing the local shear stresses. The schematic diagram of Fig. 5 shows the proposed crack propagation path that passes along the bubble-free alloy/polypropylene interface then through the bubble leaving a thin polymer layer on the alloy and a cavity within the polypropylene

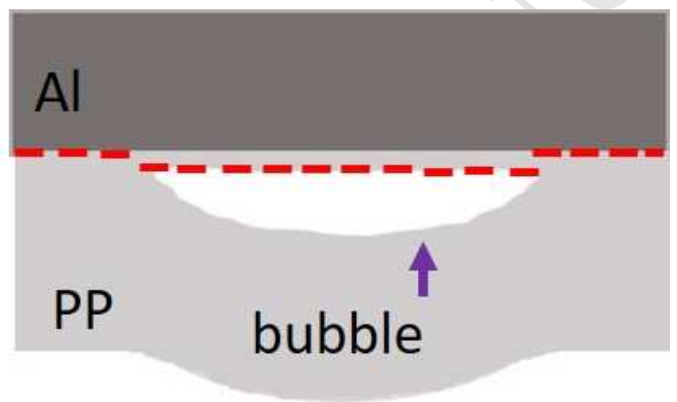

Figure 5.Schematic diagram of the fracture path through the as-rolled AA 5052 alloy/polypropylene joint. The dashed line indicates the fracture path.

3.3 Lap-shear tensile tests and fractography of joints prepared using PEO-treated alloy

Figure 6 presents the load-extension curves for joints prepared using the PEO-treated alloy either without or with a mechanical key. The failure loads are listed in Table 2. The PEO treatment provided much stronger joints and greater extensions at failure than the as-rolled and mechanical keyed alloy (Figure 2). The curves for PEO-treated joints displayed generally decreasing gradually slopes, but with transient increases, particularly at an extension of about $0.3 \mathrm{~mm}$. There was no significant influence of mechanical keying on the joint strength, which had an average value of $1322 \mathrm{~N}$, which is 21.3 times the strength of the joints prepared using the as-rolled alloy, 
and 11.8 and 5.6 times greater than the bond strengths of joints prepared using 3 and $4.5 \mathrm{~mm}$ diameter mechanical keys, respectively.

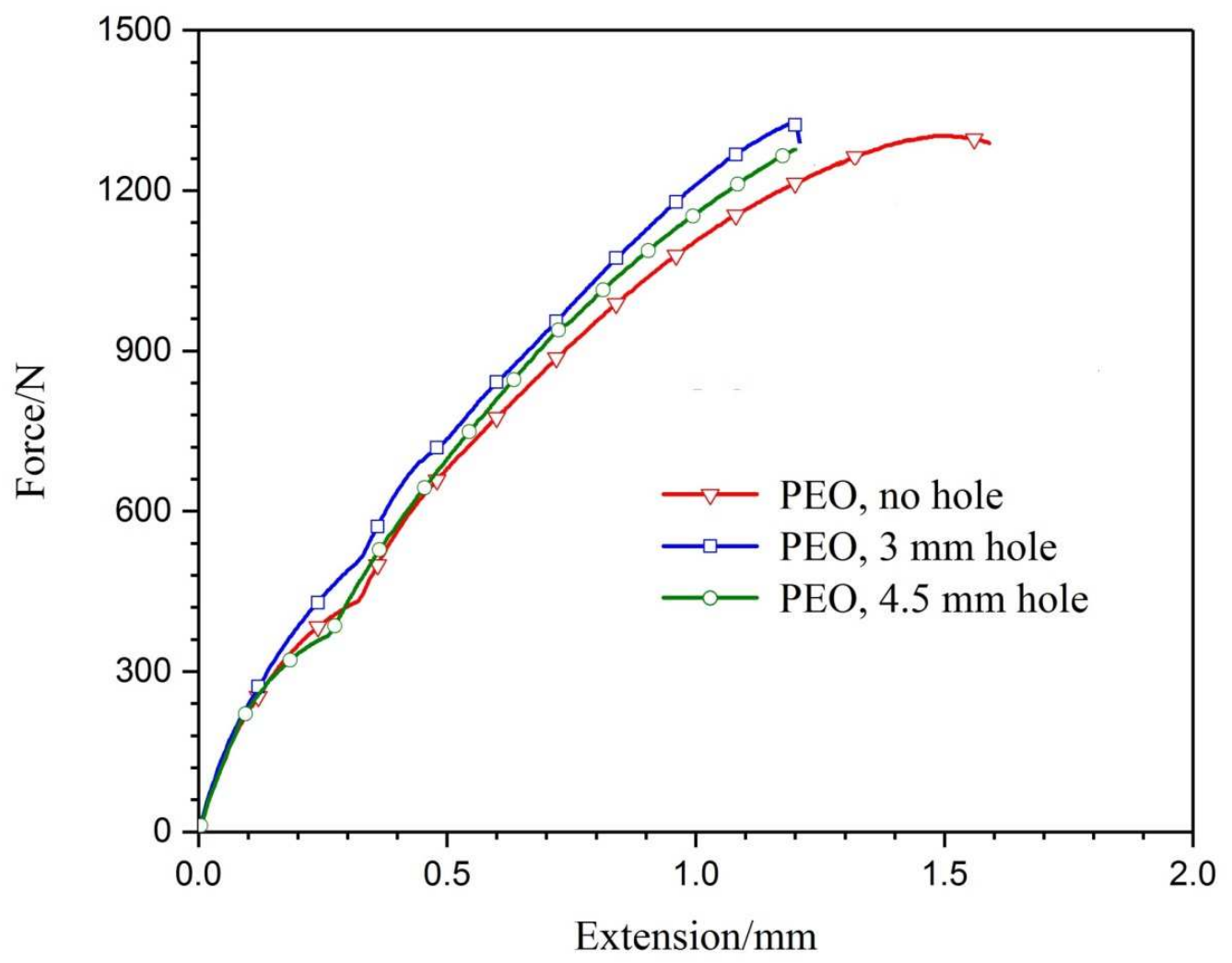

Figure 6. Force-extension curves from lap-shear tests of AA 5052 alloy/polypropylene joints with the alloy in the PEO-treated condition without and with mechanical keys.

Table 2. Failure loads of AA 5052/polypropylene joints in lap-shear tests. Three tests were carried out for each specimen condition. The average, maximum and minimum failure loads of the three tests are reported. 


\begin{tabular}{|c|c|c|c|}
\hline \multirow{2}{*}{} & Average load & Max. load & Min. load \\
\cline { 2 - 4 } & \multicolumn{3}{|c|}{ (N) } \\
\hline As-rolled & $62 \pm 10$ & 70 & 49 \\
\hline As-rolled - 3 mm hole & $112 \pm 17$ & 119 & 98 \\
\hline As-rolled - 4.5 mm hole & $238 \pm 24$ & 243 & 207 \\
\hline PEO & $1302 \pm 42$ & 1397 & 1286 \\
\hline PEO - 3 mm hole & $1321 \pm 49$ & 1564 & 1278 \\
\hline PEO - 4.5 mm hole & $1343 \pm 51$ & 1394 & 1312 \\
\hline
\end{tabular}

Figure 7 shows photographs of the fractured PEO-treated joints without and with mechanical keys. The key-free joints fractured across the polypropylene outside the joined area (Fig. 7 (a)). The specimen with a $3 \mathrm{~mm}$ key failed across the whole of the joined area, with a transverse crack forming in the polypropylene close to the key (see arrow in Fig. 7 (b). In contrast, joints with a $4.5 \mathrm{~mm}$ key failed occurred across part of the joined area on the polypropylene side of the key, with the polymer to the left of the key remaining attached to the alloy (Fig. 7 (c)). The light patches on the polypropylene in Figs. 7 (b) and 7 (c) are remnants of the PEO coating (see arrows in Fig 7 (c)). The lower failure loads of polypropylene in the joints compared with asreceived polymer (failure load $\approx 2688 \mathrm{~N}$ ) is possibly due to stress concentration caused by the mechanical keys and gas bubbles, reduction of the polypropylene thickness due to extrusion at the joint edges, and changes in the mechanical properties of the polymer due to thermal degradation.Using a thermocouple inserted tightly in a $1 \mathrm{~mm}$ diameter hole near the centre of the joint area of PEO-treated specimens prepared with and without a mechanical key, a temperature rise to $285{ }^{\circ} \mathrm{C}$ was recorded during FSSW, which is significantly above the melting point of polypropylene $\left(160^{\circ} \mathrm{C}\right)$. Owing to its low magnesium content, the heating during FSSW is not expected to cause sensitization of the alloy and susceptibility of intergranular corrosion [27-30]. 


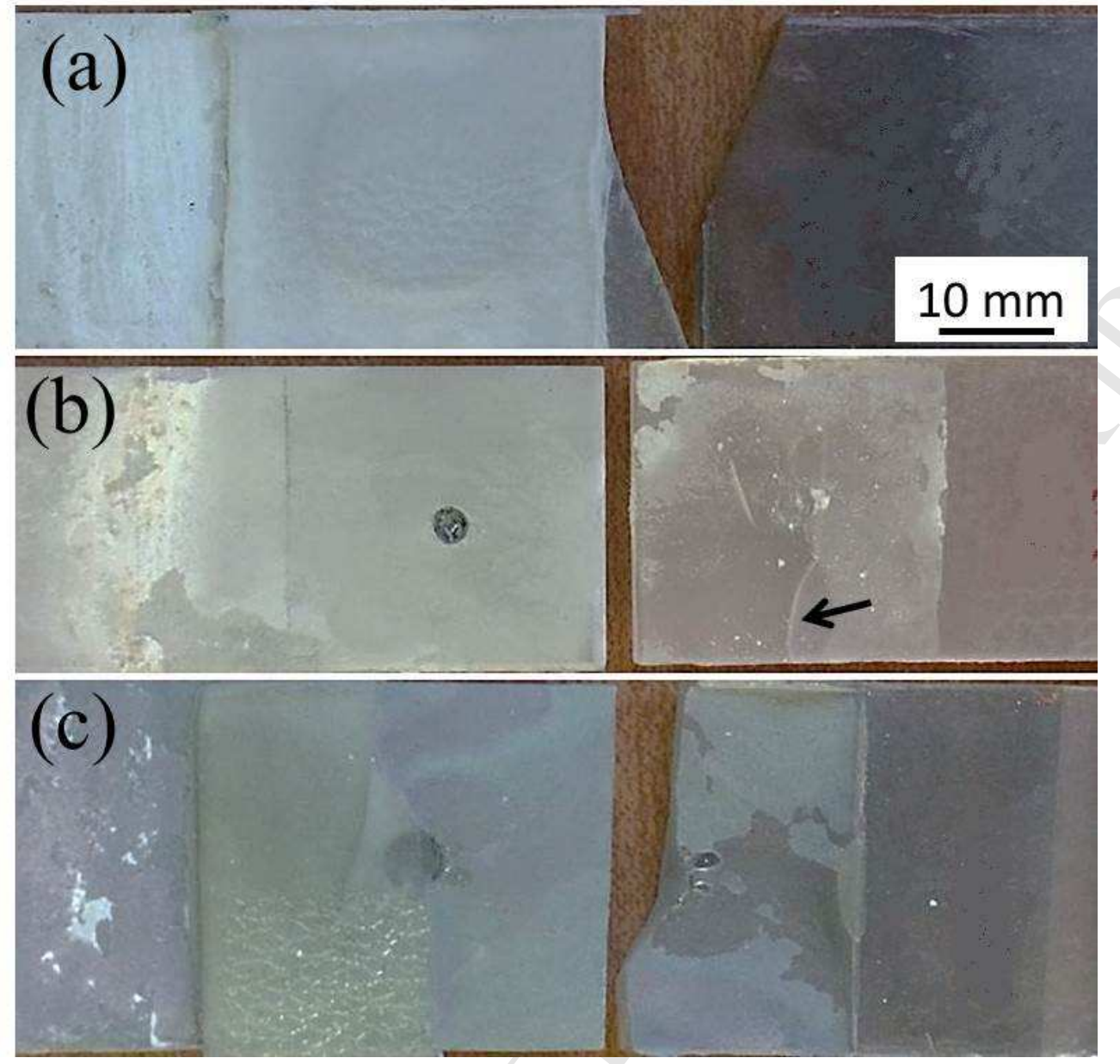

Figure 7. Photographs of fractured PEO-treated AA 5052 alloy/polypropylene joints with (a) no mechanical key, (b) AR with 3mm mechanical key and (c) $4.5 \mathrm{~mm}$ mechanical key condition.

Scanning electron micrographs of the fractured joint prepared with the PEO-treated with a 4.5 mm mechanical key are shown in Fig. 8. Figure 8 (a) shows that the polypropylene has fractured near the key. The polypropylene to the left of the key is still attached to the alloy. PEO coating is attached in parts of the polypropylene side of the joint. Figures 8 (b-1), 8 (b-2) and 8 (b-3) show details in the boxed region in Fig. 8 (a). Figure 8 (b-1) reveals the interface between the regions of attached and detached polypropylene. The fracture through the thickness of the polypropylene sheet corresponds to the light region in the bottom half of the image. The sheet had fractured by a brittle mode, which is also in evidence at the interface with the PEO-coated aluminium (see black arrow). The dark regions (see white arrows) consist of polypropylene attached to the 
coating. The boundary between the polypropylene layer and the PEO coating is shown at higher magnification in Fig. 8 (b-2). The grain-like appearance of the re-solidified polypropylene around a gas bubble is evident in the region labelled A. The PEO coating from which the polymer has detached is present in the region labelled B. However, remnants of polymer remain on the coating, as shown in Fig. 8 (b-3), which reveals fibres (white arrows) produced by plastic failure of polypropylene that has penetrated coating pores. Figures 8 (c-1), 8 (c-2) and 8 (c-3) show details of the fracture surface in the boxed region in Fig. 8 (a) on the polymer side of the fracture. Figure 8 (c-1) reveals dark regions (see white arrows) that are cavities remaining from gas bubbles, lighter regions of PEO coating and regions of intermediate contrast, which consist of fractured polypropylene. The regions are shown in more detail in Figs. 8 (c-2) and 8 (c-3), respectively. The polypropylene in the gas bubble surface had the typical grain-like appearance (see black arrow) (Fig. 8 (c-2)). The adjacent polypropylene has a fibrous appearance characteristic of ductile failure during detachment from the PEO coating. Elsewhere, the polypropylene has been sufficiently well bonded to the PEO coating to detach coating material (see black arrow) (Fig. 8 (c-3)). 


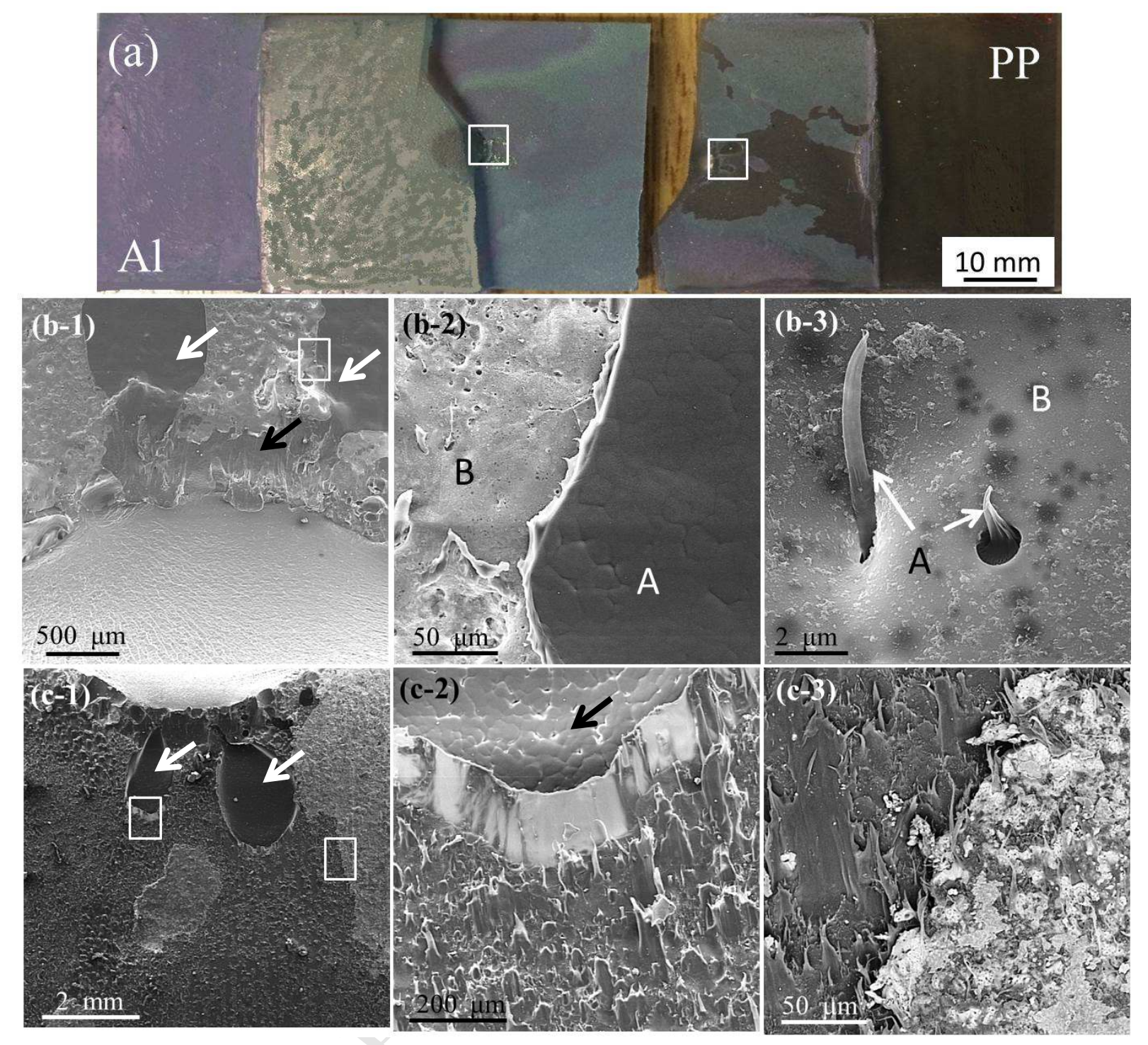

Figure 8. Scanning electron micrographs of a PEO-treated (with a $4.5 \mathrm{~mm}$ mechanical key) AA 5052 alloy/polypropylene joint: (a) fracture surfaces; (b 1-3) alloy side; (c 1-3) polypropylene side. The boxes in (a) show the locations of images in (b 1-3) (alloy side) and (c 1-3) (polymer side).

The melting and deformation of the polypropylene under the applied load during FSSW and associated thermal transient resulted in a reduction in the polymer thickness from an original value of $2.8 \mathrm{~mm}$ to $2.5 \mathrm{~mm}$ in regions outside the bubbles. The reduction is due to extrusion of polymer, which formed a thin band around the joint edges. In the centre of the bubbles on the 
polymer-side of the fractured PEO-treated joint, the minimum polymer thickness was $2.4 \mathrm{~mm}$. The thin layer of polypropylene left on the aluminium-side of bubbles was about $90 \mu \mathrm{m}$.

Further improvement in the bond strength may be obtained from modification of FSSW parameters to reduce the thermal degradation of the polymer and the number and size of gas bubbles [15]. In addition, other PEO coating and compositions and morphologies are available from the use of different electrolytes and growth condition that may provide better infiltration of polymer into porosity and improved chemical bonding between the polymer and the oxide surface.

\section{Conclusions}

1. Lap tensile shear tests of the AA 5052 alloy-polypropylene FSSW joints revealed a relatively low strength with the alloy in the as-rolled condition. The strength was enhanced by a mechanical key of 3 and $4.5 \mathrm{~mm}$ diameter, by factors of 1.8 and 3.8, respectively.

2. Pre-treatments of the alloy by PEO significantly increased the strength of joints compared with mechanical keying alone. Mechanical keying in combination with PEO provided no significant increase in bond strength compared with PEO alone. The bond strengths of the PEOtreated joints were about 21.3 times greater than those prepared using the as-rolled alloy, and 11.8 and 5.6 times greater than the bond strengths of joints prepared using the as-rolled alloy with 3 and $4.5 \mathrm{~mm}$ diameter mechanical keys, respectively.

3. In the absence of PEO, the as-rolled and mechanically-keyed conditions led to bond failure at, or close to, the alloy/polypropylene interface under comparatively low loads. The PEO coated joints showed a mixed mode of failure, with regions of crack propagation at, or close to, the coating/polymer interface, and regions of cohesive failure of the PEO coating.

4. The temperature of the alloy increased to $285^{\circ} \mathrm{C}$ during FSSW. Owing to the heating, gas bubbles formed within the polypropylene due to thermal degradation of the polymer during FSSW. 
5. The gas bubbles formed close to the alloy substrate. A thin film of polymer remained attached to the alloy at locations of bubbles following failure of the joints due to the shielding of the shear stress on the alloy/polymer interface at the bubble locations.

\section{Acknowledgements}

Authors acknowledge funding from the European Union's Horizon 2020 research and innovation programme under the Marie Skłodowska-Curie grant agreement No. 665593 awarded to the Science and Technology Facilities Council (STFC-UKRI). The authors also are grateful to Iran's National Elites Foundation (BMN) for support of this work through a postdoctoral fellowship.

\section{References}

1. A. Abibe, M. Sônego, J. F. Dos Santos, L. B. Canto, S. T. Amancio-Filho, On the feasibility of a friction-based staking joining method for polymer-metal hybrid structures. Mater. Design 92 (2016) 632-642.

2. M. S. Seong, T. H. Kim, K. H. Nguyen, J. H. Kweon, J, H. Choi, A parametric study on the failure of bonded single-lap joints of carbon composite and aluminum. Compos. Struct. 86 (2008) 135-145.

3. A. Rudawska, Adhesive joint strength of hybrid assemblies: Titanium sheet-composites and aluminium sheet-composites-Experimental and numerical verification, Int. J. Adhes. Adhes. 30 (2010) 574-582.

4. S.-G. Kang, M.-G. Kim, C.-G. Kim, Evaluation of cryogenic performance of adhesives using composite-aluminum double-lap joints, Compos. Struct. 78 (2007) 440-446. 
5. R. Matsuzaki, M. Shibata, A. Todoroki, Reinforcing an aluminum/GFRP co-cured single lap joint using inter-adherend fiber, Composites Part A 39 (2008) 786-795.

6. S.T. de Freitas, J. Sinke, Failure analysis of adhesively-bonded metal-skin-to-compositestiffener: Effect of temperature and cyclic loading, Compos. Struct. 166 (2017) 27-37.

7. L. Blaga, R. Bancilă, J. dos Santos, S. Amancio-Filho, Effect of the friction riveting process parameters on the joint formation and performance of $\mathrm{Ti}$ alloy/short-fibre reinforced polyether ether ketone joints. Mater. Design, 50 (2013) 825-829.

8. A. Abibe, S. Amancio-Filho, J. Dos Santos, E. Hage, Mechanical and failure behaviour of hybrid polymer-metal staked joints, Mater. Design, 46 (2013) 338-347.

9. Won-Bae Lee, Yun-Mo Yeon, Seung-Boo Jung, The joint properties of dissimilar formed Al alloys by friction stir welding according to the fixed location of materials, Scripta Mater. 49 (2003) 423-428.

10. Won-Bae Lee, Martin Schmuecker, Ulises Alfaro Mercardo, Gerhard Biallas, and Seung-Boo Jung, Interfacial reaction in steel-aluminum joints made by friction stir welding, Scripta Mater. 55 (2006) 355-358.

11. P. Xue, D.R. Ni, D. Wang, B.L. Xiao, Z.Y. Ma, Effect of friction stir welding parameters on the microstructure and mechanical properties of the dissimilar $\mathrm{Al}-\mathrm{Cu}$ joints, Mater. Sci. Eng. A 528 (2011) 4683-4689.

12. J. Esteves, S. Goushegir, J. Dos Santos, L. Canto, E. Hage, S. Amancio-Filho, Friction spot joining of aluminum AA6181-T4 and carbon fiber-reinforced poly(phenylene sulfide): Effects of process parameters on the microstructure and mechanical strength, Mater. Design, 66 (2015) 437-445. 
13. Natália M. André, Seyed M. Goushegir, Jorge F. dos Santos, Leonardo B. Canto, Sergio T. Amancio-Filho, Friction Spot Joining of aluminum alloy 2024-T3 and carbon-fiber-reinforced poly(phenylene sulfide) laminate with additional PPS film interlayer: Microstructure, mechanical strength and failure mechanisms, Composites Part B: 94 (2016) 197-208.

14. S. Amancio-Filho, C. Bueno, J. Dos Santos, N. Huber, E. Hage, On the feasibility of friction spot joining in magnesium/fiber-reinforced polymer composite hybrid structures, Mater. Sci. Eng: A 528 (2011) 3841-3848.

15. F. C. Liu, K. Nakata, J. Liao, S. Hirota, H. Fukui, Reducing bubbles in friction lap welded joint of magnesium alloy and polyamide, Sci. Technol. Weld. Joi. 19 (2014) 578-587.

16. H. K. Pabandi, M. Movahedi, A. H. Kokabi, A new refill friction spot welding process for aluminum/polymer composite hybrid structures. Compos. Struct. 174 (2017) 59-69.

17. A. L. Yerokhin, X. Nie, A. Leyland, A. Matthews, S. J. Dowey Plasma electrolysis for surface engineering, Surf. Coat. Technol. 203 (2009) 3410-3419.

18. A. L. Yerokhin, L. O. Snizhko, N. L. Gurevina, A. Leyland, A. Pilkington, A. Matthews, Discharge characterization in plasma electrolytic oxidation of aluminium, J. Phy. D: Appl. Phys. 36 (2003) 2110-2120.

19. Vahid Dehnavi, Xing Yang Liu, Ben Li Luan, David W. Shoesmith, Sohrab Rohani, Phase transformation in plasma electrolytic oxidation coatings on 6061 aluminum alloy, Surf. Coat. Technol. 251 (2014) 106-114.

20. J.A. Curran, T.W. Clyne, Porosity in plasma electrolytic oxide coatings, Acta Mater. 54 (2006) 1985-1993.

21. F. Liu, J. Liao, K. Nakata, Joining of metal to plastic using friction lap, Mater. Design, 54 (2014) 236-244. 
22. S. Aliasghari, M. Ghorbani' P. Skeldon, H. Karami and M. Movahedi, Effect of plasma electrolytic oxidation on joining of AA 5052 aluminium alloy to polypropylene using friction stir spot welding, Surf. Coat. Technol. 313 (2017) 274-281.

23. V. Purohit, R. A. Orzel, Polypropylene: a literature review of the thermal decomposition products and toxicity, J. Am. Coll. Toxicol. 7 (1988) 221-242.

24. Jeffery D. Peterson, Sergey Vyazovkin, Charles A. Wight, Kinetics of the thermal and thermo-oxidative

degradation of polystyrene, polyethylene and poly(propylene), Macromol. Chem. Phys. 2001, $202,775-784$.

25. Yoshio Tsuchiya, Kikuo Sumi, Thermal decomposition products of polypropylene, J. Polym. Sci. A 7 (1969) 1599-1607.

26. J. Gersten, V. Fainberg, G. Hetsroni, Y. Shindler, Kinetic study of the thermal decomposition of polypropylene, oil shale, and their mixture, Fuel 79 (2000) 1679-1686.

27. J. L. Searles, P. I. Gouma, R.G. Buchheit RG, Stress corrosion cracking of sensitized AA5083 (Al-4.5Mg-1.0Mn), Metall. Mater Trans A 32 (2001) 2859-2867.

28. I. N. A. Oguocha, O. J. Adigun, S. Yannacopoulos, Effect of sensitization heat treatment on properties of Al-Mg alloy AA 5083-H116, J. Mater. Sci. 43 (2008) 4208-4214.

29. Gaosong Yi, Yakun Zhu, Erik Sundberg, Alexander T. Derrick, Michael L. Free, Sensitization prediction and validation for al 5xxx alloys exposed to long-term cyclical and constant heating at low temperatures, Corrosion 72 (2016) 177-186. 